\title{
Sian kasvukäyrän geneettiset parametrit
}

\author{
Minna Koivula, Marja-Liisa Sevón-Aimonen, Ismo Stranden, Kaarina Vuori, Esa Mäntysaari
}

MTT, Kotieläintuotannon tutkimus, Eläinjalostus, 31600 Jokioinen, etunimi.sukunimi@mtt.fi

Kasvun mallintamiseen on käytetty monia matemaattisia menetelmiä. Gompertzin funktio on osoittautunut sopivaksi kuvaamaan sikojen kasvua. Sian kasvu noudattaa epälineaarista, s:n muotoista käyrää, jota voidaan kuvata helposti Gompertzin funktiolla. Kasvukäyrän tärkeimmät tekijät ovat aikuispaino ja aikuistumissuhde eli kasvun suhteellista nopeutta kuvaava kerroin. Aikuispainon ja aikuistumissuhteen avulla voidaan laskea sian paino missä tahansa iässä. Tässä tutkimuksessa tarkoituksena on laskea geneettiset tunnusluvut suoraan kasvukäyrän eri parametreille ja tutkia mahdollisuutta käyttää niitä jalostusarvostelussa. Tutkimusaineisto koostui vuosilta 2000 - 2005 kantakoeasemilta kerätyistä sikojen punnitustiedoista. Aineistossa oli kaikkiaan 122071 havaintoa 10111 yorkshire-rotuisen sian viikoittaisesta painosta $30 \quad-100 \quad \mathrm{~kg}$ välillä. Sikakohtaiseen elopainoaineiston analysointiin käytettiin menetelmää, joka perustuu Gompertzin funktion linearisointiin Taylorin sarjan avulla. Tätä varten on MTT:1lä kehitetty MiX99- ja DMU-ohjelmiin perustuva sovellus. Menetelmässä iteratiivisesti vuorotellaan kasvukäyrän parametrien ja varianssikomponenttien estimointia siten, että kasvukäyrän parametrien estimointi suoritetaan MiX99:1lä ja tämän jälkeen lasketaan niiden varianssikomponentit DMU:1la. MiX99 ja DMU ohjelmia vuorotellaan, kunnes päästään lähelle todellisia ratkaisuja ja varianssikomponenttien ja kiinteiden tekijöiden muutos iterointikierrosten välissä on tarpeeksi pieni. Kasvukäyrän parametrien periytymisasteet olivat suhteellisen korkeita ( 0.31 ja 0.54 välillä). Jotta voitiin verrata, miten hyvin kasvukäyrämallin ja jalostusavojen laskennassa käytössä olevan kantakoekasvun antamat jalostusarvot täsmäävät, kasvukäyristä laskettiin keskimääräiset päiväkasvut karjuille 30 ja 100 kg välillä. Karjuista valittiin lähempään tarkasteluun ne, joilla oli vähintään 15 jälkeläistä aineistossa. Kun nämä karjut listattiin käyristä lasketun keskimääräisen kasvunopeuden suhteen paremmuusjärjestykseen, voitiin havaita, että 10 parhaan karjun joukossa 8 oli samoja molemmilla malleilla. Kantakoekasvun ja kasvukäyrämallien antamat jalostusarvot siis vastaavat hyvin toisiaan. Kasvukäyrämalli on kuitenkin luotettavampi, koska erot alku- tai loppupainossa eivät vaikuta yhtä paljoa. Kasvukäyrämallia käytettäessä voidaan valita myös itse kasvukäyrän muotoa, ei pelkästään keskimääräistä kasvunopeutta. Kasvukäyrän parametreja ei tällä hetkellä valita missään sian jalostusohjelmassa suoraan. Jalostusohjelmien suunnittelussa olisi kuitenkin tärkeää tuntea alkukasvun, lihasikavaiheen kasvun ja aikuispainon, samoin kuin aikuistumissuhteen väliset geneettiset yhteydet. Käyrän tuntemisen myötä voidaan myös ympäristötekijät mallintaa paremmin sekä suunnitella sikojen ruokinta ja teurastusajankohta tarkemmin.

Avainsanat: Kasvukäyrä, Gompertz-funktio 


\section{Johdanto}

Kasvun mallintamiseen on käytetty monia matemaattisia menetelmiä. Gompertzin funktio on osoittautunut sopivaksi kuvaamaan sikojen kasvua (Emmans ja Kyriazakis 1999, Wellock ym. 2004). Sian kasvu noudattaa epälineaarista, s:n muotoista käyrää, jota voidaan kuvata helposti Gompertzin funktioilla. Kasvukäyrän tärkeimmät tekijät ovat aikuispaino ja aikuistumissuhde. Aikuistumissuhde kuvaa kasvun suhteellista nopeutta eli sitä, miten nopeasti sika lähestyy aikuispainoa. Aikuispainon ja aikuistumissuhteen avulla voidaan laskea sian paino missä tahansa iässä (Sevón-Aimonen 2004). Jalostusvalinta kasvunopeuden ja lihakkuuden suhteen muuttaa kasvukäyrän parametreja. Muutoksen suunta ja määrä riippuvat siitä, mihin ominaisuuteen ja kasvun vaiheeseen valinta kohdistuu. Viime vuosina käytetyn keskimääräisen kasvunopeuden valinnan on otaksuttu nostaneen sikojen aikuistumissuhdetta (Knap 2000). Aikuispainon ja aikuistumissuhteen välillä vallitsee yleisesti negatiivinen korrelaatio: kun aikuispaino kasvaa, aikuistumissuhde pienenee Tässä tutkimuksessa tarkoituksena on laskea geneettiset tunnusluvut suoraan kasvukäyrän eri parametreille ja tutkia mahdollisuutta käyttää niitä jalostusarvostelussa.

\section{Aineisto ja menetelmät}

Tutkimusaineisto koostui vuosilta 2000 - 2005 kantakoeasemilta kerätyistä sikojen punnitustiedoista. Aineistossa oli kaikkiaan 122071 havaintoa 10111 yorkshire-rotuisen sian viikoittaisesta kasvusta 30$100 \mathrm{~kg}$ välillä. Eläimet olivat 7471 pahnueesta ja aineistossa oli kaikkiaan 4544 leikkoa, 2967 imisää ja 2600 karjua. Painomuuttujalle tehtiin ennen analysointia logaritmimuunnos, koska residuaalit kasvavat painon noustessa. Sikakohtaiseen elopainoaineiston analysointiin käytettiin menetelmää, joka perustuu Gompertzin funktion linearisointiin Taylorin sarjakehitelmän avulla. Tätä varten on MTT:1lä kehitetty MiX99- ja DMU-ohjelmiin perustuva sovellus (Vuori ym. 2004). Tässä menetelmässä vuorotellaan iteratiivisesti kasvukäyrän parametrien ja varianssikomponenttien estimointia siten, että kasvukäyrän parametrien estimointi suoritetaan MiX99:1lä ja tämän jälkeen lasketaan niiden varianssikomponentit DMU:lla. MiX99 ja DMU ohjelmia vuorotellaan, kunnes päästään lähelle todellisia ratkaisuja ja varianssikomponenttien ja kiinteiden tekijöiden muutos iterointikierrosten välissä on tarpeeksi pieni.

Sian kasvumallin oletetaan olevan:

$$
\mathrm{y}_{\mathrm{ij}}=\alpha_{\mathrm{i}} \exp \left(-\beta_{\mathrm{i}} \exp \left(-\kappa_{\mathrm{i}} \mathrm{t}_{\mathrm{j}}\right)\right) * \mathrm{e}_{\mathrm{ij}},
$$

missä $y_{i j}$ on yksilön ${ }_{i}$ paino iässä ${ }_{j}$, $t_{j}$ on ikä (päivää), $a_{i}$ on aikuispaino, $\hat{a}_{i}$ on alkupainon ja aikuispainon suhteen logaritmi ja $\hat{\mathrm{e}}$ on aikuistumissuhde. Logaritmiaineistolle laskettuna kasvukäyrä muuttuu muotoon:

$$
\operatorname{lny}_{\mathrm{ij}}=\ln \alpha_{\mathrm{i}}-\beta_{\mathrm{i}} \exp \left(-\kappa_{\mathrm{i}} \mathrm{t}_{\mathrm{j}}\right)+\ln \mathrm{e}_{\mathrm{ij}} .
$$

Kasvukäyrän parametrien analysoinnissa käytettiin isämallia:

$$
\mathrm{y}_{\mathrm{ijklmn}}=\mathrm{ssy}_{\mathrm{i}}+\mathrm{sex}_{\mathrm{j}}+\mathrm{l}_{\mathrm{k}}+\mathrm{a}_{\mathrm{l}}+\mathrm{s}_{\mathrm{m}}+\mathrm{e}_{\mathrm{ijklmn},}
$$

missä $y_{j k l m n}$ on kasvukäyrän parametri $(\alpha, \beta, \kappa)$, mallin kiinteinä tekijöinä ovat erä $\left(s s y_{i}\right)$, sukupuoli $\left(\operatorname{sex}_{\mathrm{j}}\right)$. Satunnaistekijöinä ovat pahnue $\left(\mathrm{l}_{\mathrm{k}}\right)$, ei-geneettinen eläintekijä $\left(\mathrm{a}_{\mathrm{l}}\right)$, sekä isä $\left(\mathrm{s}_{\mathrm{m}}\right)$. $\mathrm{e}_{\mathrm{j} j \mathrm{klmn}}$ on jäännöstermi.

\section{Tulokset ja tulosten tarkastelu}

Kasvukäyrämallissa kasvukäyrän parametreille määritetään lineaarinen jalostusarvostelumalli ja kun koko malli ratkaistaan, jokainen eläin saa jalostusarvon käyrän eri parametreille. Tällöin voidaan tarkastella myös eri yksilöiden kasvukäyriä ja nähdä, missä vaiheessa kasvu eroaa eri yksilöillä. Tällä 
hetkellä käytettävässä mallissa lasketaan jalostusarvot kantakoekasvulle eli keskimääräiselle päiväkasvulle $30-100 \mathrm{~kg}$ välillä.

Kasvukäyrän eri parametrien geneettiset ja fenotyyppiset varianssit sekä parametrien periytymisasteet esitetään taulukossa 1 . Varianssit ja heritabiliteetit on laskettu isämallilla, mutta varianssit on muutettu vastaamaan eläinmallin variansseja. Kasvukäyrän parametrien periytymisasteet ovat suhteellisen korkeita ( 0.31 ja 0.54 välillä), joten niihin perustuva valinta on mielekästä. Kantakoekasvun periytyvyysaste samalle aineistolle on 0.48 . Taulukossa 2 esitetään parametrien väliset geneettiset ja fenotyyppiset korrelaatiot. Aikuispainon ja aikuistumissuhteen välillä on voimakas negatiivinen korrelaatio, kuten yleisesti on havaittu. Ainoa positiivinen yhteys havaitaan aikuispainon ja alkupainon ja aikuispainon suhteen, eli $\beta$ :n, välillä.

Taulukko 1. Geneettiset (G) ja fenotyyppiset (P) varianssit sekä periytyvyysasteet kasvukäyrän kolmelle parametrille.

\begin{tabular}{|l|l|l|l|l|}
\hline Parametri & $\mathbf{G}$ & $\mathbf{P}_{(\text {pahnue })}$ & $\mathbf{P}_{(\mathrm{eläin})}$ & $\mathbf{h}^{\mathbf{2}}$ \\
\hline $\mathbf{a}$ & 651.76 & 322.29 & 498.75 & 0.44 \\
\hline$\hat{\mathbf{a}}$ & 0.0368 & 0.0119 & 0.0191 & 0.54 \\
\hline$\hat{\mathbf{e}}$ & 0.00000248 & 0.00000168 & 0.00000376 & 0.31 \\
\hline
\end{tabular}

Taulukko 2. Kasvukäyräparametrien väliset geneettiset (alakolmio) ja fenotyyppiset (yläkolmio) korrelaatiot

\begin{tabular}{|l|l|l|l|}
\hline Parametri & $\boldsymbol{\alpha}$ & $\boldsymbol{\beta}$ & $\mathbf{K}$ \\
\hline $\boldsymbol{\alpha}$ & & 0.90 & -0.86 \\
\hline $\boldsymbol{\beta}$ & 0.88 & & -0.82 \\
\hline $\mathbf{K}$ & -0.80 & -0.80 & \\
\hline
\end{tabular}

Jotta voidaan verrata, miten hyvin kasvukäyrämallin ja nykyisin jalostusarvojen laskennassa käytössä olevan kantakoekasvun antamat jalostusarvot täsmäävät, kasvukäyristä laskettiin keskimääräiset päiväkasvut karjuille 30 ja $100 \mathrm{~kg}$ välillä. Karjuista valittiin lähempään tarkasteluun ne, joilta oli vähintään 15 jälkeläistä aineistossa. Kun nämä karjut listattiin käyristä lasketun keskimääräisen päiväkasvunopeuden suhteen paremmuusjärje stykseen, voitiin havaita, että 10 parhaan karjun joukossa 8 oli samoja molemmilla malleilla. Kantakoekasvun ja kasvukäyrämallien antamat jalostusarvot siis vastaavat hyvin toisiaan. Kuvassa 1 esitetään kasvukäyrästä lasketun keskimääräisen päiväkasvun perusteella parhaan ja huonoimman karjun kasvukäyrät (samat karjut ovat myös kantakoekasvumallin perusteella paras ja huonoin). Kuvassa 2 esitetään samojen karjujen päiväkasvun kehitys suhteessa painon kehitykseen. Karjujen kasvukäyrissä ei sinänsä ole paljoa eroa, mutta jos tarkastelee niiden päiväkasvua 30 ja 100 kg:n välillä, ero on selkeä. Kasvukäyrämallia käytettäessä voidaankin valita myös itse kasvukäyrän muotoa, ei pelkästään keskimääräistä kasvunopeutta.

Kuva 1. Kasvukäyristä lasketun keskimääräisen päiväkasvun suhteen parhaan ja huonoimman karjun kasvukäyrät.

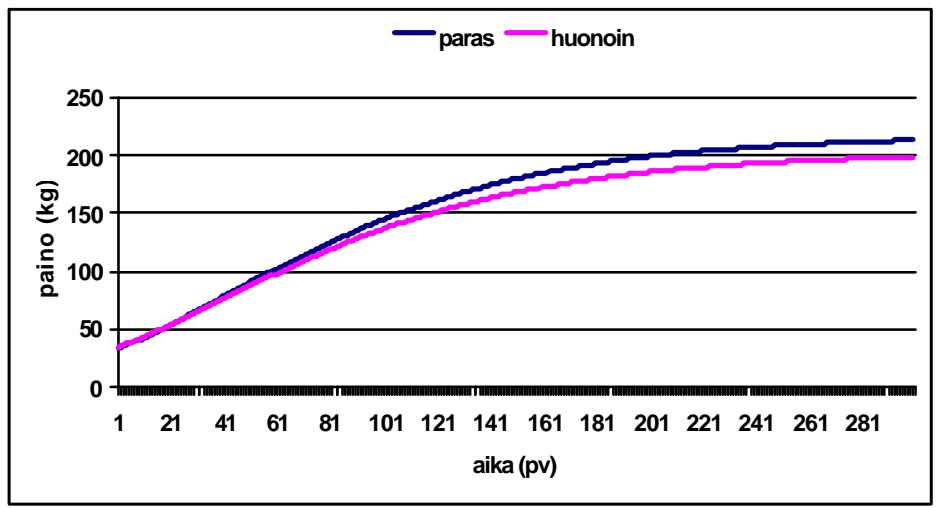


Kuva 2. Kasvukäyristä lasketun keskimääräisen päiväkasvun suhteen parhaan ja huonoimman karjun päivittäinen kasvu 30 ja 100 kg välissä.

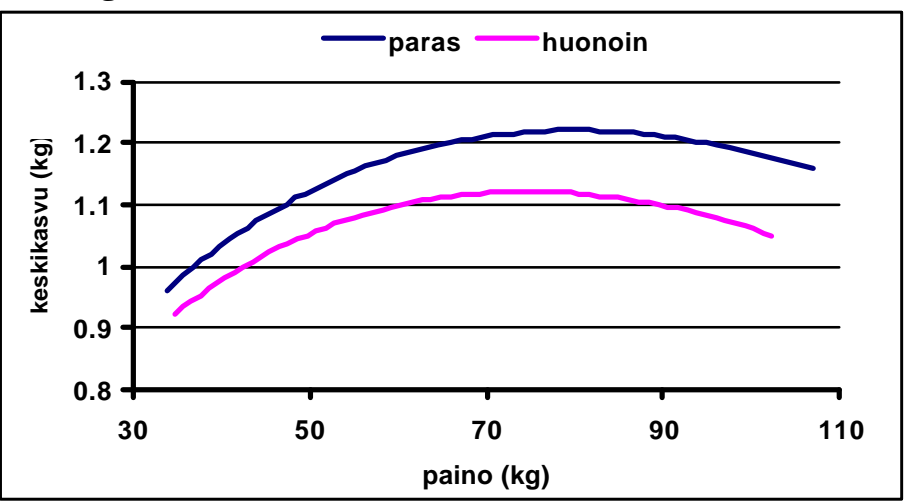

Kasvukäyrän parametreista aikuispainon jalostusarvot korreloivat selvästi kantakoekasvun jalostusarvojen kanssa (kuva 3). Eli valitsemalla aikuispainoa valitaan myös kasvunopeutta. Saman voi havaita myös kuvasta 4, jossa ovat tässä arvioidut geneettiset trendit aikuispainolle ja kantakoekasvulle. Aikuistumissuhteen ja kantakoekasvun välillä oli heikko positiivinen korrelaatio, eikä aikuistumissuhteen geneettinen trendi ollut yhtä selkeä. Tässä tutkimuksessa kuitenkin käytettiin suhteellisen lyhyttä aikajaksoa (havainnot vuosilta 2000-2005), joten geneettisten trendien osoittaminen on vaikeaa.

Kuva 3. Karjujen aikuispainon ja kantakoekasvun jalostusarvojen korrelaatio

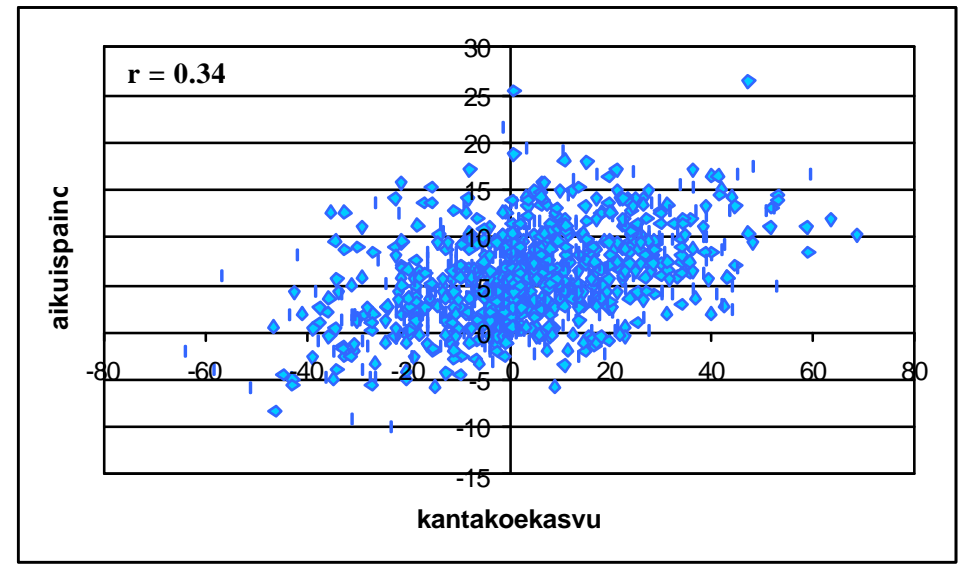

Kuva 4. Kantakoekasvun ja aikuispainon geneettinen trendi karjun syntymävuoden mukaan

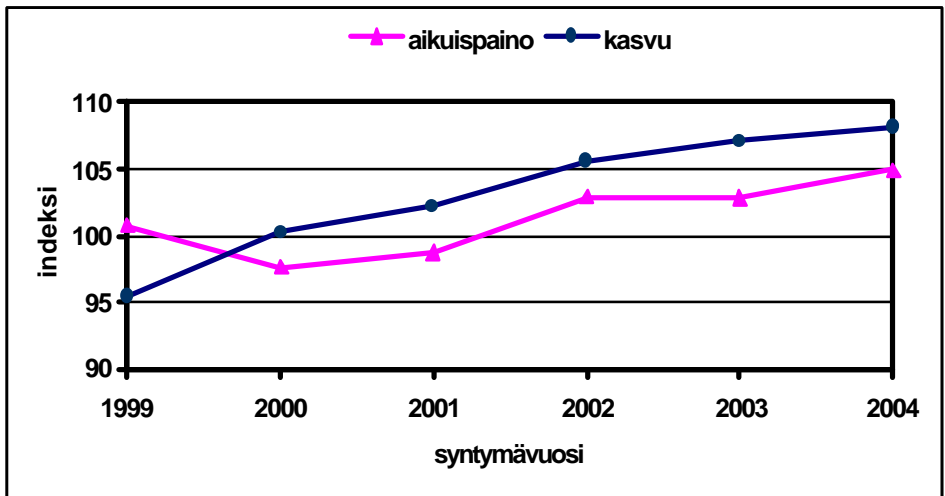




\section{Johtopäätökset}

Missään jalostusohjelmassa ei tällä hetkellä tietoisesti tehdä valintaa kasvukäyrän parametrien suhteen. Jalostusohjelman suunnittelussa olisi kuitenkin tärkeää tuntea alkukasvun, lihasikavaiheen kasvun ja aikuispainon, samoin kuin aikuistumissuhteen väliset geneettiset yhteydet. Kasvukäyrän parametrien jalostusarvojen avulla voidaan tarvittaessa kasvukäyrän muotoa muuttaa valinnalla. Käyrän tuntemisen myötä voidaan myös ympäristötekijät mallintaa paremmin sekä suunnitella sikojen ruokinta ja teurastusajankohta tarkemmin. Näin ollen kasvun ilmaiseminen käyrän parametrein on monella tapaa hyödyllistä. Kasvukäyrämalli on antaa myös luotettavammat jalostusarvot, koska erot alku- tai loppupainossa eivät vaikuta yhtä paljoa kuin keskimääräisen kasvun jalostusarvoihin. Tämä on huomioitava viimeistään siinä vaiheessa, kun uusi sikojen kantakoeasema ja kertatyhjennyssysteemi otetaan käyttöön.

\section{Kirjallisuus}

Emmans, G.C. ja Kyriazakis, I. 1999. Growth and body compositions. A quantitative biology of the pig (toim. I. Kyriazakis), s. 181-197.

Knap, P.W. 2000. Variation in maintenance requirements of growing pigs in relation to body composition. A simulation study. PhD thesis, University of Wageningen.

Sevón-Aimonen, M.-L. 2004. Kasvun rajoille. Sika 4:34-35.

Wellock, I.J., Emmans, G.C., \& Emmans, I. 2004. Describing and predicting potential growth in the pig. Animal Science 78:379-388.

Vuori, K. Stranden, I., Sevón-Aimonen, M.-L., Mäntysaari, E 2004. Estimation of Compertz growth curve parameters by a nonlinear mixed effects model. Book of abstracts of the 55th Annual meeting of the European Association for Animal Production (toim. Ynze van der Honing). Annual meeting of the European Association for Animal Production, s. 300. 